\title{
Increasing Retention in Engineering and Computer Science with a Focus on Academically At-Risk First Year and Sophomore Students
}

\section{Dr. Sharon A. Jones P.E., University of Portland}

SHARON A. JONES is Dean of the Shiley School of Engineering at the University of Portland. Her research focuses on decision-making for environmental and infrastructure systems. Dr. Jones received a BS in Civil Engineering from Columbia University, and a PhD in Engineering and Public Policy from Carnegie Mellon University. She is a licensed professional engineer in California.

Ms. Zulema Naegele, University of Portland

STEP Retention Counselor

Dr. Tammy VanDeGrift, University of Portland

Dr. Tammy VanDeGrift is an associate professor of computer science and the associate dean for the Shiley School of Engineering at the University of Portland. Her research interests in computer science education include perceptions of the field, student preconceptions, and student values. She is also interested in broadening participation in computer science and served as a co-editor for special issues on broadening participation in computing for K-12 and post-secondary education for the ACM Transactions on Computing Education. 


\section{Increasing Retention in Engineering and Computer Science with a Focus on Academically At-Risk First Year and Sophomore Students}

\section{Introduction}

The program described in this paper seeks to increase retention rates for engineering and computer science students and to evaluate the effectiveness of best practices for retention of academically at-risk students. The main hypothesis is that students who fall behind their cohort early in their college career are less likely to be retained in engineering and computer science. As such, we focus this project on the academically "at-risk" student group defined as first-year college students who are not calculus ready and sophomores who are missing up to two courses necessary to be classified as part of their class-level cohort.

This NSF-funded STEP grant project started in the 2013 - 2014 academic year at the University of Portland, a private, Catholic comprehensive university serving approximately 3500 undergraduate students; of those, approximately 650 are in the School of Engineering. The Shiley School of Engineering is undergraduate-focused and student-centered; as such, the faculty's primary responsibility is to teach, advise, and mentor undergraduates. Several student life offices and tutoring centers support student engagement and development at the university. The 10-year $(2001-2011)$ retention rate from $1^{\text {st }}$ semester to $3^{\text {rd }}$ semester for engineering and computer science students is $77 \%$, but most stay at the university with a different major.

In Fall 201355 academically "at-risk" students were encouraged to participate in a voluntary, ongoing retention program directed by the STEP retention counselor. Of the 55, 33 participated in the retention program through regular meetings with the STEP retention counselor and through attendance at academic workshops, such as time management and test-taking strategies. Other components of the retention program include networking dinners with alumni, meeting with the staff at the learning resource center, attending professional society meetings, meeting with staff at Career Services, and one-on-one advising sessions with the STEP retention counselor.

\section{Engineering Retention Program}

More specifically, the retention program consists of weekly individual or group meetings with the STEP retention counselor and attendance at academic and career workshops. In Table 1, topics for meetings with the counselor are shown for each month. 
Table 1: Meetings with STEP Retention Counselor

\begin{tabular}{|l|l|l|l|} 
Counselor Meetings & \multicolumn{1}{c}{ Topic 1 } & \multicolumn{1}{c}{ Topic 3 2} \\
\hline September & Program Introductions & Academic Updates & Survey of Interests \\
\hline October & Mid-term grades & Learning Styles & Study skills \\
\hline November & $\begin{array}{l}\text { Professor Office } \\
\text { Hours }\end{array}$ & Tutoring & Finals schedule \\
\hline December & Resume critique & Externship application & Winter Break Plans \\
\hline
\end{tabular}

In Table 2, topics and the number of students in attendance at each of the workshops are shown for each month.

Table 2: Engineering Academic and Professional Workshops

\begin{tabular}{|l|l|l|l|}
\multicolumn{1}{l}{ Workshops } & \multicolumn{1}{c}{ Topic 1 } & \multicolumn{1}{l}{ Number of Attendees } \\
\hline September & Time Management & & 10 \\
\hline October & Test Taking Strategies & Tutoring Coordination & 10,5 \\
\hline November & Alumni Mixer & Writing & 12,5 \\
\hline
\end{tabular}

3. Formative Assessment: Data gathered from the End of Semester Survey

In December 2013, data was gathered from an end of semester survey given to the 55 academically at-risk first-year and second-year engineering students. Table 3 describes the survey responders and Table 4 summarizes how they responded. Recall that 33 of the 55 students voluntarily participated in the retention counseling sessions and the professional workshops. These 33 belong to the "Participant" categories shown in Table 3. The other 22 comprise the "Non-participant" categories. Furthermore, first-year students who did not place into calculus started behind in the curriculum and are in the category "Start Behind". Secondyear students who are behind their cohort by up to two courses are in the "Fall Behind" category.

The survey was a formative assessment tool to evaluate the first semester of implementation of the STEP Retention Program. The survey questions are based on Tinto's Model of Retention $^{[4,6,9,14]}$. They support the attributes of Academic and Social Integration to the University, which in turn will assess the student's success.

Table 3: Survey Participants

\begin{tabular}{|l|l|l|l|}
\multicolumn{1}{|c}{ Year } & \multicolumn{3}{c|}{ Fall 2013 Math Course Number of Resp. } \\
\hline $\begin{array}{l}\text { Start Behind Non- } \\
\text { participant (SBN) }\end{array}$ & First-year & Pre-Calculus 2 & 2 responses \\
\hline $\begin{array}{l}\text { Start Behind } \\
\text { Participant (SBP) }\end{array}$ & First-year & Pre-Calculus 2 & 13 responses \\
\hline $\begin{array}{l}\text { Fall Behind Non- } \\
\text { participant (FBN) }\end{array}$ & Second-year & Calculus 1 or 2 & 0 responses \\
\hline $\begin{array}{l}\text { Fall Behind } \\
\text { Participant (FBP) }\end{array}$ & Second-year & Calculus 1 or 2 & 7 responses \\
\hline
\end{tabular}


Table 4: Survey responses based on Tinto's Model of Retention

A. Questions supporting Academic Integration focusing on prior qualifications and attributes

SBN: High school course confidence was low

Academic skills were average

SBP: High school course confidence was spread out, but mostly good or high Academic skills high

FBN: No responses

FBP: High school course confidence was spread out, but mostly good Academic skills were mostly high

B. Questions supporting Social Integration focusing on teaching, learning, support, facilities, and sense of belongingness

SBN: Sense of belonging was high

SBP: Sense of belonging was mostly high, with a couple low

FBN: No responses

FBP: Sense of belonging was mostly high

C. Questions supporting Social and Academic Integration, meetings with STEP Counselor and Academic Workshops

SBN: Did not attend, therefore questions were not asked

SBP: Overall, students felt counselor meetings and workshops were beneficial, learned something new, and would recommend to others

FBN: No responses

FBP: Overall, students felt counselor meeting and workshops were beneficial, learned something new, and would recommend to others

D. Open ended questions supporting both Academic and Social Integration SBN: Did not find the need to attend workshops or meetings with counselor, felt supported enough already at University of Portland. Would have liked to attend a workshop in math or physics

SBP: Appreciated help and advice provided by the STEP retention counselor, felt comfortable talking with retention counselor, meetings were individual and personal, very informative

FBN: No responses

FBP: STEP retention counselor was positive and offered lots of suggestions, talked about issues in personal life, was able to talk openly about progress and steps to take, interested in workshops on how to study smarter and get schoolwork done faster, more class specific help available, more workshops on where an engineering degree can take them 
Overall, the responses from the survey show that the students who attended the retention counselor meetings and the academic and professional workshops found the experiences to be positive and beneficial. From the meetings with the retention counselor, students are quoted as saying:

$>$ "She knew my situation and loved to listen and offer advice."

$>$ "The most helpful aspect would be the advice that I took from Zuly about how to graduate in 4 years, despite being behind. The option of summer classes and just having options in general was truly comforting."

$>$ "Being able to openly talk about my progress and get advice on what steps I should take or direction I should go."

Students who attended the academic workshops were quoted as saying:

$>$ "The writing workshop gave me what I believe will be valuable information for when I do take a writing course here at UP”.

$>$ The people who represent the workshops are knowledgeable in their respective areas."

\section{Engineering Summer Bridge Program}

Currently under development, a summer bridge program will offer pre-calculus 2 and Introduction to Theology for $\sim 14$ incoming first-year students who do not test into calculus. During late-June to early-August, these students will live on campus, attend both classes, attend workshops and tutoring sessions, meet engineers, and visit engineering sites and companies.

\section{Conclusion}

Both programs will be assessed using institutional research data: tracking the retention of "at risk" students who participate in the programs, "at-risk" students who do not participate in the programs, and the "not at-risk" students. In addition to the quantitative metrics, data gathered from focus groups and surveys will be used to identify best practices and areas for improvement for these programs. Based on quantitative and qualitative data, the goal of this project is to use, improve, and disseminate best practices for retaining first- and second-year engineering and computer science students.

\section{Acknowledgements}

The authors thank the students who participated in the retention program and the students who provided feedback about the program.

This material is based upon work supported by the National Science Foundation under award number DUE - 1317238 and is supported in part by funds given to the National Science Foundation by the Intel Foundation and the GE Foundation. Any opinions, findings, and conclusions or recommendations expressed in this material are those of the author(s) and do not necessarily reflect the views of the National Science Foundation. 


\section{References}

1. American Society for Engineering Education. 2012. Going the Distance: Best Practices and Strategies for Retaining Engineering. Engineering Technology, and Computing Students. http://www.asee.org/retentionproject

2. American Society for Engineering Education. 2009. Creating a Culture for Scholarly and Systematic Innovation in Engineering Education. http://www.asee.org/about-us/the-organization/advisorycommittees/CCSSIE

3. Bernold, Leonhard, E., Spurlin, Joni, E., Anson, Chris, M., 2007. Understanding Our Students: A Longitudinal-Study of Success and Failure in Engineering With Implications for Increased Retention. Journal of Engineering Education. pp. 263 - 274.

4. Besterfield-Sacre, M., Atman, C., and Shuman L. J. 1998. Engineering Student Attitudes Assessment. Journal of Engineering Education. 87:2, pp. 133-141.

5. Carberry, Adam, R., Lee, Hee-Sun, Ohland, Matthew, W. 2010. Measuring Engineering Design selfEfficacy. Journal of Engineering Education. pp. 71 - 79.

6. Eris, Ozgur, Chachra, Debbie, Chen, Helen, Sheppard, Sheri, Ludlow, Larry, Rosca, Camelia, Bailey, Tori, Toye, George. 2010. Outcomes of Longitudinal Administration of the Persistence in Engineering Survey. Journal of Engineering Education. pp. 371-395.

7. Hartman, Harriet, Hartman, Moshe. 2006. Leaving Engineering: Lessons from Rowan University's College of Engineering. Journal of Engineering Education. pp. $49-61$.

8. Hutchison, M. A., Follman, D. K., Sumpter, M., and Bodner, G. M. 2006. Factors Influencing the SelfEfficacy Beliefs of First-Year Engineering Students. Journal of Engineering Education. 91:1, pp. 39 - 47.

9. Jones, S. A. 2008. Impact of the POSSE Program on the Academic Integration of Minority Engineering Students. In Proceedings of the Frontiers in Education Conference, Saratoga Springs, NY.

10. Li, Qing, Swaminathan, Hariharan, Tang, Jiong. 2009. Development of a Classification System for Engineering Student Characteristics Affecting College Enrollment and Retention. Journal of Engineering Education. pp. 361- 376.

11. Marra, Rose, M., Rodgers, Kelly, A., Shen, Demei, Bogue, Barbara. 2012. Leaving Engineering: A Multi-Year Single Institution Study. Journal of Engineering Education. pp. 6 - 27.

12. Oregon State University. 2013. Louis Stokes Alliance for Minority Participation Program. http://lsamp.oregonstate.edu

13. Portland State University. 2013. Louis Stokes Alliance for Minority Participation Program. http://www.pdx.edu/lsamp

14. Tinto, V. 1987. Leaving College. Chicago: University of Chicago Press.

15. Tinto, V. 1988. Stages of Student Departure: Reflection on the Longitudinal Character of Student Leaving. Journal of Higher Education. 59:4. pp 438 - 455.

16. University of Washington. 2013. Women in Science and Engineering. http://www.engr.uw.edu/wise

17. University of Southern California. 2013. Center for Engineering Diversity. http://www.viterbi.usc.edu 